\title{
Autofagia en el sistema cardiovascular: pasado, presente y futuro
}

\author{
Andrea Ramírez-Sagredo ${ }^{1, *}$, Larissa Aleman ${ }^{1, *}$, Mónica Villa ${ }^{1}$, \\ Myra N Chávez ${ }^{1,2}$ Lorena García $^{1}$, Sergio Lavandero ${ }^{1,3, \#}$ \\ 1 Advanced Center for Chronic Diseases (ACCDiS) \& Centro Estudios Moleculares de la Célula (CEMC). Facultad de Ciencias \\ Químicas y Farmacéuticas y Facultad de Medicina, Universidad de Chile, Santiago, Chile. \\ 2 FONDAP Center for Genome Regulation (CGR), Facultad de Ciencias, Universidad de Chile, Santiago, Chile. \\ 3 Cardiology Division, Department of Internal Medicine, University of Texas Southwestern Medical Center, Dallas, Texas, USA \\ *Ambas son primeras autoras y contribuyen de igual manera a este manuscrito
}

\section{Resumen:}

La enfermedad cardiovascular se mantiene como la principal causa de morbimortalidad a nivel mundial a pesar de los avances científicos y tecnológicos recientes, por esto existe la necesidad de búsqueda de nuevas dianas terapéuticas.

La autofagia es un mecanismo de degradación de proteínas y organelos disfuncionales que ocurre en vacuolas especializadas de doble membrana denominadas autofagosomas y que requiere la participación de los lisosomas. Este proceso permite el auto abastecimiento celular de energía a través del reciclaje de diversos substratos energéticos. Se activa en respuesta a diversas formas de estrés, principalmente debido a la ausencia de nutrientes y su presencia ha sido caracterizada en todos los tipos celulares que componen el sistema cardiovascular. Existe una ventana de actividad de autofagia óptima la que se relaciona con la mantención de la homeostasis cardiovascular y su desregulación participa en la patogénesis de diversas patologías cardiovasculares.

En este artículo se revisa el curso temporal que llevó el descubrimiento de la autofagia, la contribución al área del Dr. Ohsumi, reciente Premio Nobel de Medicina, los principales conceptos, mecanismos celulares y moleculares de la formación del autofagosoma, nodos de regulación y sintetizamos su participación en la homeostasis del corazón y en la patogénesis de las enfermedades cardiovasculares y sus perspectivas futuras.

\section{Correspondencia:}

Dr. Sergio Lavandero.

Advanced Center for Chronic Diseases (ACCDiS), Facultad de Ciencias Químicas y Farmacéuticas/Facultad Medicina, Universidad de Chile. slavander@uchile.cl. 


\section{Cardiovascular autophagy: past, present and future}

Cardiovascular disease continues to be the leading cause of morbi-mortality worldwide despite the recent scientific and technological advances. Therefore, more research is needed to discover novel therapeutic targets.

Autophagy mediates the removal of dysfunctional proteins and organelles. This process takes place in double-membrane vesicles, named autophagosomes, which later fuse with lysosomes. The mechanism allows self-renewal energy repletion through diverse energy substrate recycling. Diverse forms of cellular stress, mainly nutrient deprivation, activate this process. Autophagy has been widely characterized within the cells of the cardiovascular system. There is a window of optimal autophagy activity implicated in maintaining cardiovascular homeostasis and its dysregulation participates in the pathogenesis of different cardiovascular diseases.

In this article, we review the time course of autophagy discovery, the Nobel Prize winner Dr. Ohsumi contribution, main concepts, mechanisms involved in autophagosome formation and its regulatory nodes. Additionally, we summarized the role of autophagy in cardiovascular homeostasis and pathogenesis and future perspectives.

Key words: Autophagy, autophagosome, cardiovascular disease. 


\section{Introducción}

Las enfermedades cardiovasculares siguen siendo la causa principal de mortalidad a nivel mundial, su prevalencia es de larga data y sigue expandiéndose rápidamente ${ }^{1}$. Por ello se requiere identificar los mecanismos responsables de su génesis y desarrollo, así como investigar nuevas terapias que prevengan o mitiguen sus consecuencias ${ }^{1}$.

En estas últimas tres décadas se han descubierto nuevos mecanismos degradativos que operan en todas nuestras células y que permiten mantener su homeostasis al remover organelos y proteínas envejecidos o alterados ${ }^{2}$. Hay dos procesos degradativos básicos denominados vía proteosomal y vía autofágica ${ }^{3}$. Su desregulación permite la acumulación de organelos y proteínas disfuncionales y se ha asociado al desarrollo de diversas patologías cardíacas $^{4}$. Los estudios pioneros del efecto del ayuno y glucagón en el hígado de animales, así como la privación de nutrientes en levaduras llevaron al descubrimiento de una cascada de complejos eventos que conducen al secuestro de proteínas y organelos, para su posterior entrega al lisosoma $^{5}$. Este proceso denominado autofagia es un mecanismo catabólico, altamente conservado en la evolución y presente en todas las células eucarióticas ${ }^{3}$. Este proceso participa en un amplio rango de eventos fisiológicos que requieren la degradación y renovación de componentes celulares como adaptación metabólica, respuesta al estrés y control de calidad intracelular. Su desregulación funcional se vincula con enfermedades cardiovasculares, neurodegenerativas y cáncer y por ello ha tenido un atractivo y creciente interés en las ciencias médicas y biológi$\operatorname{cas}^{3}$ (Figura 1).

\section{Autofagia: un proceso de canibalismo celular}

Etimológicamente la palabra autofagia deriva del griego "auto" "phagein" y significa "comerse a sí mismo", lo cual refleja lo observado a través de microscopía electró- nica, donde se visualizan vesículas de doble membrana que albergan organelos y componentes citoplasmáticos en diferentes estados de degradación ${ }^{5}$. Inicialmente, la autofagia se describió como la activación de un proceso de degradación en respuesta al estrés nutricional. Así, de Duve y colaboradores descubrieron la presencia de autofagosomas en el hígado que se generan en respuesta al ayuno y glucagón y de esta forma proporcionar aminoácidos para la generación de energía o la formación de nuevas proteínas ${ }^{5}$. La autofagia está presente como mecanismo catabólico desde la etapa neonatal en mamíferos. El mayor inductor fisiológico de autofagia es la depleción y limitación de diversos nutrientes como glucosa, aminoácidos, factores de crecimiento y oxígeno ${ }^{3}$. En presencia de nutrientes, las reacciones anabólicas predominan dentro de la célula y la autofagia se mantiene en niveles bajos para la homeostasis y sobrevida celular ${ }^{3}$.

El resultado de la activación de autofagia es la captura y degradación de porciones de citoplasma; los productos generados contribuyen así a la provisión de sustratos para procesos de biosíntesis y al restablecimiento de los niveles energéticos intracelulares, así como también contribuyen a la liberación de energía que sirva como sustrato en la eliminación de organelos defectuosos ${ }^{2}$. Sin embargo, una activación de autofagia excesiva y descontrolada conlleva a la depleción de moléculas y organelos esenciales provocando una muerte celular autofágica.

\section{Premio Nobel de Medicina 2016: autofagia}

En 1960, luego de que el científico belga Christian de Duve (Premio Nobel de Medicina de 1974) describiera al lisosoma, comenzaron observaciones que mostraban gran cantidad de contenido celular, e incluso organelos enteros que podían encontrarse dentro de este organelo. También los resultados sugerían que parecía haber una estrategia celular que le suministrara grandes cargas de

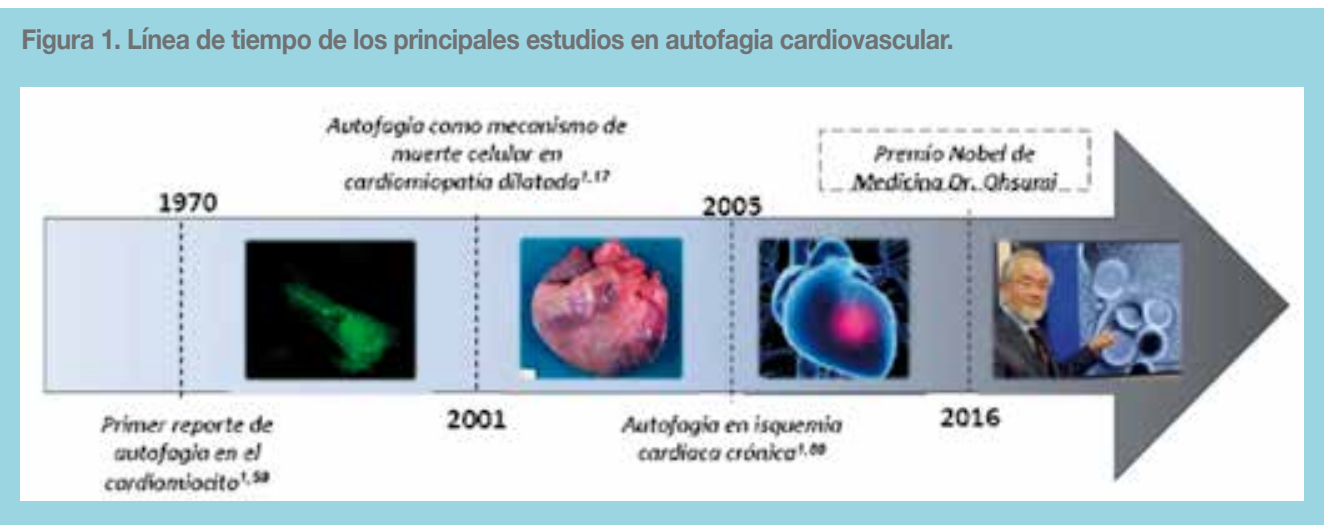




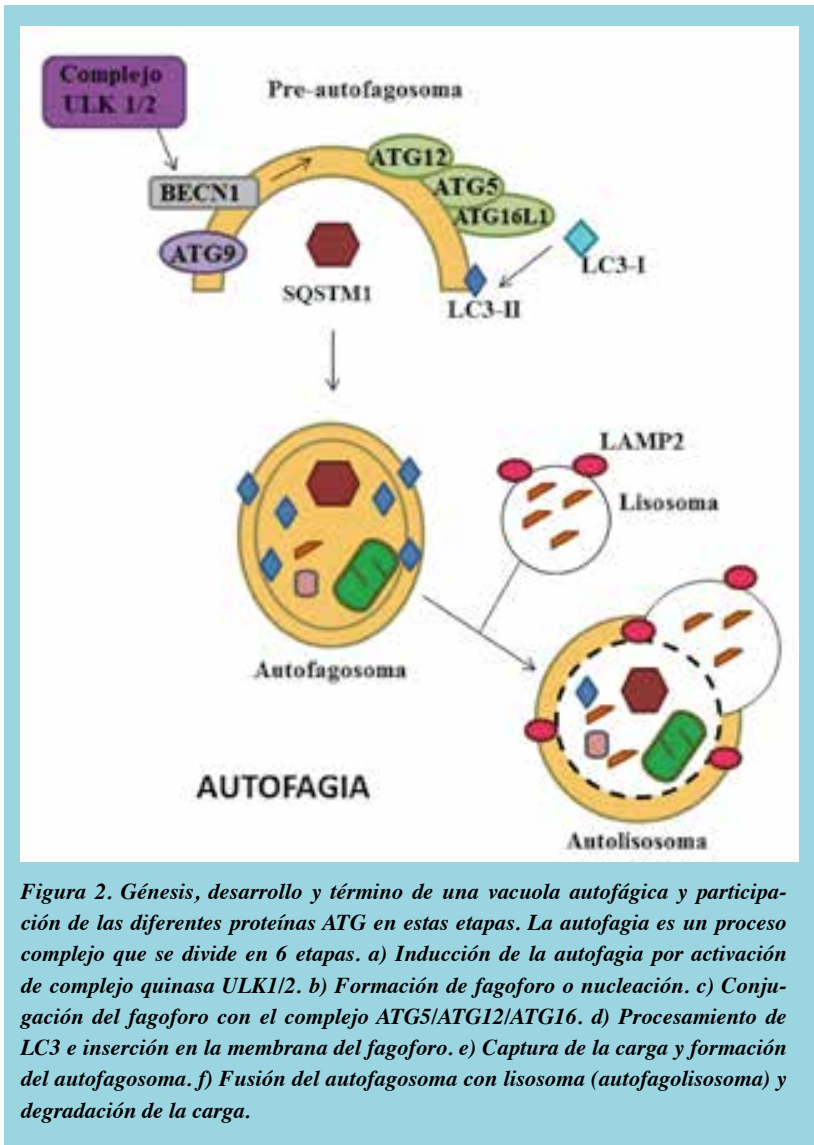

contenido intracelular al lisosoma para su degradación. Ésta estrategia fue revelada por el mismo Christian de Duve, quien describió el proceso de autofagia e identificó una nueva vesícula que transporta carga al lisosoma, llamada autofagosoma 5 .

En el año 1992, el Profesor Yoshinori Ohsumi (Tokyo Institute of Technology) describió el proceso de autofagia ("canibalismo celular") en levaduras, pero su aporte más importante fue describir 15 genes que son esenciales en este proceso ${ }^{6}$. Posteriormente, las proteínas codificadas por estos genes claves se caracterizaron funcionalmente y se estableció que su participación en una serie de complejos que regulan las distintas fases de iniciación y formación del autofagosoma ${ }^{7}$. Con la caracterización de elementos claves en la señalización celular se conoció que la autofagia requiere de complejos e intrincados procesos que incluyen la dinámica de membranas, tráfico de vesículas y posterior degradación de la "carga"; permitiendo dividir toda la cascada autofágica en las siguientes etapas (Figura 2): a) inducción, reconocimiento y selección de carga, b) formación de vesículas, c) fusión de vacuolas y formación del autofagolisosoma, d) descomposición de la carga y liberación de productos de degradación y e) termino $^{3,6,8}$.

\section{Mecanismos moleculares de la autofagia}

Cuando las células son sometidas a condiciones de estrés tales como hipoxia, privación de nutrientes, altas temperaturas, infección por patógenos y estrés oxidativo se activan una serie de proteínas reguladoras de la autofagia (mTORC1, AMPK, PKA, etc.) que a su vez regulan la actividad del complejo quinasa ULK, compuesto por las proteínas ULK1/2, ATG13, FIP200 y ATG10117,18. La principal proteína de este complejo, la quinasa ULK1 activa por fosforilación a la proteína Beclin1 (también conocida como ATG6) que forma parte del complejo iniciador de la nucleación del fagóforo, el cual genera 3-fosfatidil inositol fosfato (PIP3), esencial para el reclutamiento de otras proteínas ATGs sobre las dobles membranas lipídicas provenientes del retículo endoplásmico, el complejo de Golgi y las mitocondrias ${ }^{11,12}$. La expansión de la doble membrana lipídica para la posterior formación del autofagosoma se produce por la interacción del fagoforo con el complejo proteico ATG5/ATG12, el cual se forma por la acción de ATG7 y ATG10 ${ }^{13}$. Finalmente, la unión de ATG16 al complejo ATG5/ATG12 produce su multimerización y formación de un gran complejo que permite la inserción de la proteína LC3-II (también conocida como ATG8) en la membrana del fagóforo ${ }^{14}$. La proteína LC3 (microtubule-associated protein light chain 3) se sinteriza inicialmente de forma no procesada como pro-LC3), la cual rápidamente es escindida por la acción de ATG4, generándose la forma activa LC3-I en el citosol. Posteriormente, al LC3-I se incorpora lípidos por la acción de ATG7 y ATG3 que catalizan su unión a los residuos de fosfadiletanolamina presentes abundantemente en la membrana del fagóforo ${ }^{15}$. Si bien hasta la fecha la función del LC3-II no se conoce, se sabe que esa unión al fagoforo es fundamental para el cierre de la vesícula posterior a la captación de la carga y dar origen al autofagosoma ${ }^{16}$. Una vez formado el autofagosoma se libera el complejo ATG5/ATG12/ATG16 y el LC3-II se libera de la membrana externa por acción de autofagina ${ }^{14}$. Este autofagosoma desnudo se fusiona con los lisosomas por acción de las proteínas Rab7, Lamp1 y Lamp2 ${ }^{14}$. Finalmente, el cargo se degrada por enzimas lisosomales presentes en el autofagolisosoma ${ }^{16}$. Las diversas metodologías para evaluar la autofagia se describen en el cuadro 1. 


\section{Cuadro 1.}

\section{¿Cómo estudiar la autofagia?}

Existen diversas metodologías para investigar la activación, inhibición o alteración del flujo autofágico, cada uno de ellos con distintas ventajas y desventajas, por lo que se recomienda usar técnicas complementarias. Estos métodos siguen la formación y acumulación de autofagosomas, así como su fusión con los lisosomas y la degradación de su contenido en las mismas. Se debe distinguir entre aumento o reducción del número de eventos autofágicos y el incremento o disminución del flujo autofágico. Esta distinción se efectúa usando inhibidores de fusión o degradación lisosomal. Ambos aspectos deben ser siempre comparados al nivel basal de autofagia en el sistema estudiado, el cual debe ser previamente definido en condiciones carentes de estímulos. A continuación se describen las principales metodologías en uso para estudiar la autofagia y mayores detalles se encuentra en el artículo de Klionsky et al. ${ }^{1}$

Microscopía electrónica de compartimentos autofagosomales. Técnica considerada como "gold standard" en el estudio del autofagia. Es la única técnica que visualiza a nivel subcelular los compartimentos formados durante la autofagia. A través de ella es posible identificar los autofagosomas como una vesícula rodeada de una doble membrana, además de identificar el origen del cargo a degradar que contienen, el cual puede incluir orgánulos (mitocondrias, peroxisomas, ribosomas, entre otros) o contenido citoplasmático diverso, permitiendo de esta forma una distinción entre autofagia selectiva y no selectiva. Sin embargo, este método permite únicamente una evaluación a un solo tiempo de un proceso altamente dinámico, por lo que la evaluación de distintas muestras a distintos tiempos es necesaria ${ }^{2}$. Una variante de esta metodología es la immuno-microscopía electrónica de transmisión, que utiliza anticuerpos incorporados con partículas de oro coloidal, los cuales han sido diseñados para unirse a proteínas cargo-especificas dentro de los autofagosomas o bien verificar el origen autofágico de las vesículas utilizando anticuerpos específicos contra el LC3 endógeno ${ }^{3}$, la primera molécula en ser identificada como parte de la maquinaria de la autofagia en mamíferos ${ }^{4}$.

Inmunocitoquimica e inmunofluorescencia en la visualización de la autofagia. La inmunocitoquímica ha sido usada para determinar la co-localización de distintos orgánulos o proteínas endógenas con los compartimentos autofagosomales y lisosomas en las células, y de esta forma observar su direccionamiento y degradación por medio de la autofagia. Además del uso de anticuerpos primarios específicos para las proteínas $\operatorname{LC} 3^{5}$ y Beclin $1^{6}$ que se están involucradas en la formación de autofagosomas, o anticuerpos específicos contra proteínas mitocondriales (e.g. PINK1) o lisosomales (e.g. LAMP1), existen sondas fluorescentes tales como BO-

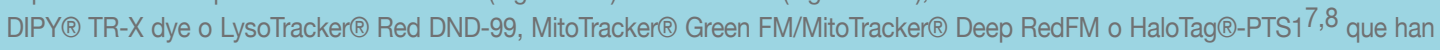
sido usados para marcar específicamente los lisosomas, mitocondrias y peroxisomas, respectivamente. Su visualización a través de un microscopio confocal determina la co localización de las proteínas o compartimentos gracias al solapamiento de las señales de los fluoróforos que se distingue en un color específico en las imágenes compuestas. Además, muchos de estos protocolos han sido ya adaptados a técnicas como la citometría de flujo, que permiten un análisis de carácter más cuantitativo de los eventos ${ }^{911}$.

Inmunofluorescencia y el flujo autofágico. Existe también la posibilidad de insertar constructos transgénicos en las células u organismos utilizados en la investigación, que permiten la expresión de proteínas relacionadas con autofagia, unidas a proteínas fluorescentes. Tal es el caso, por ejemplo del constructo codificante para GFP-LC3, el cual ha sido usado frecuentemente para monitorear la inducción de autofagia y formación de autofagosomas. En circunstancias basales la proteína GFP-LC3 se encuentra uniformemente distribuida en el citoplasma, no obstante cuando se activa la autofagia, el GFP-LC3 es reclutado a la membrana fagosomal, generando señales fluorescentes puntuales en la célula, las cuales pueden ser cuantificadas y comparadas al número de puntos con respecto al grupo control. Adicionalmente, la fluorescencia de la proteína GFP tiene además la característica de ser sensible al pH ácido, lo cual ha permitido el diseño de constructos más atractivos para el estudio del flujo autofágico ${ }^{12}$. Uno de estos es el constructo tándem mRFP/ mCherry-GFP-LC3 ${ }^{13}$, que permite la detección de autofagosomas previo a la fusión con el lisosoma (la señal fluorescente de GFP y RFP/mCherry es visible) y comparar su incidencia con respecto a los autolisosomas (únicamente la señal de RFP presente, dado que la proteína es más estable en el ambiente lisosomal) ${ }^{14}$. Recientemente, este constructo fue adaptado para generar el reportero GFP-LC3-RFP-LC3 $\Delta G^{15}$. Por medio de este, es posible medir el flujo autofágico de LC3, dado que el procesamiento proteolítico del péptido a través de Atg4 permite comparar cantidades equimolares de GFP-LC3 (reclutado a autofagosomas, y finalmente degradado) y RFP-LC3 $\triangle G$ (se mantiene como control interno de síntesis en el citoplasma). Otras proteínas cuya sensibilidad al pH hace que el principio de este constructo funcione de forma más robusta son Venus (menos sensible al pH que GFP, mayor intensidad en su fluorescencia que mRFP ${ }^{16}$ y mWasabi (más sensible al pH que GFP, y no es fluorescente en ambientes ácidos ${ }^{17}$. Además, se ha explorado el uso de proteínas fluorescente fotoconvertibles, tales como Dendra ${ }^{18}$, que permite distinguir entre la síntesis del LC3 exógeno y su reclutamiento a los fagoporos, o los sistemas PS-CFP2 y EosFP-GABARAP ${ }^{19}$ diseñados para estudiar eventos puntuales relacionados con la autofagia. Junto a estos constructos, el uso de las proteínas fluorescentes que tienen la característica de espectros de emisión distintos de acuerdo al $\mathrm{pH}$ en el que se encuentran, tales como Rosella ${ }^{20}$ y Keima ${ }^{21}$ ), permiten también el estudio y seguimiento de la degradación orgánulo-especifica por medio de la autofagia $22-24$. 
Biología molecular para cuantificar índice de autofagia. A nivel molecular es posible establecer el aumento o disminución de la autofagia por Western Blot. Uno de los principales parámetros que se determina es la proporción de la proteína LC3-conjugada al lípido fosfatidiletanolamina (LC3-II) en comparación a la proteina no lipidada (LC3-I). A consecuencia de su distinta movilidad electroforética es posible distinguir una de otra en geles de poliacrilamida con dodecilsulfato sódico (SDS-PAGE; LC3-I 16-18 kDa; LC3-II 14-16 kDa) y un aumento en la proporción LC3-II:LC-I indica en general una acumulación en el número de autofagosomas ${ }^{25}$. Adicionalmente, es común que se reporte la relación SQSTM1/p62:Beclin1 como índice de la estimulación de la autofagia, dado que existe una correlación en la disminución en los niveles de SQSTM1/p62 y el aumento en BECN1 con un aumento en la autofagia ${ }^{26}$.

1. Klionsky DJ, et al. Guidelines for the use and interpretation of assays for monitoring autophagy (3rd edition). Autophagy 12:1-222, 2016.

2. Eskelinen E-L, Reggiori F, Baba M, Kovacs AL, Seglen PO. Seeing is believing: The impact of electron microscopy on autophagy research. Autophagy 7:935-56, 2011.

3. Mayhew TM. Quantitative immunoelectron microscopy: alternative ways of assessing subcellular patterns of gold labeling. Methods Mol Biol 369:309-29, 2007

4. Kabeya Y et al. LC3, a mammalian homologue of yeast Apg8p, is localized in autophagosome membranes after processing. EMBO J 19:5720-8, 2000.

5. Tanida I et al., LC3 and Autophagy. Methods Mol Biol.445:77-88, 2008.

6. Cao Y, Klionsky, DJ. Physiological functions of Atg6/Beclin 1: a unique autophagy-related protein. Cell Res 17:839-849, 2007.

7. Lang C et al. HaloTag (TM): a new versatile reporter gene system in plant cells. J Exp Botany 57:2985-92, 2006.

8. Huybrechts SJ et al. Peroxisome dynamics in cultured mammalian cells. Traffic 10:1722-33, 2009.

9. Shvets $\mathrm{E}$ et al. Utilizing flow cytometry to monitor autophagy in living mammalian cells. Autophagy 4:621-8, 2008.

10. Eng KE et al. A novel quantitative flow cytometry-based assay for autophagy. Autophagy 6:634-41, 2010.

11. Mauro-Lizcano M et al. New method to assess mitophagy flux by flow cytometry. Autophagy 11:833-43, 2015.

12. Mizushima $\mathrm{N}$ et al. Methods in mammalian autophagy research. Cell 140: 313-326, 2010.

13. Kimura $\mathrm{S}$ et al. Dissection of the autophagosome maturation process by a novel reporter protein, tandem fluorescent-tagged LC3. Autophagy 3:452-60, 2007

14. Kaizuka T et al. An Autophagic flux probe that releases an internal control. Mol Cell 64:835-849, 2016.

15. Rekas A et al. Crystal structure of venus, a yellow fluorescent protein with improved maturation and reduced environmental sensitivity. J Biol Chem 2002; 277:50573-8;

16. Zhou $\mathrm{C}$ et al. Monitoring autophagic flux by an improved tandem fluorescent-tagged LC3 (mTagRFP-mWasabi-LC3) reveals that high-dose rapamycin impairs autophagic flux in cancer cells. Autophagy 8:1215-26, 2012.

17. Gurskaya NG et al. Engineering of a monomeric green-to-red photoactivatable fluorescent protein induced by blue light. Nat Biotechnol 24:461-5, 2006.

18. Koga $\mathrm{H}$ et al. A photoconvertible fluorescent reporter to track chaperone-mediated autophagy. Autophagy 12:892-3, 2016.

19. Joachim J, Tooze SA. GABARAP activates ULK1 and traffics from the centrosome dependent on Golgi partners WAC and GOLGA2/ GM130. Nat Commun 2:386, 2011.

20. Rosado CJ et al. Rosella: a fluorescent pH-biosensor for reporting vacuolar turnover of cytosol and organelles in yeast. Autophagy 4:205-13, 2008.

21. Katayama $\mathrm{H}$ et al. A sensitive and quantitative technique for detecting autophagic events based on lysosomal delivery. Chem Biol18:1042-52, 2011.

22. Ryhanen T et al. Crosstalk between Hsp70 molecular chaperone, lysosomes and proteasomes in autophagy-mediated proteolysis in human retinal pigment epithelial cells. J Cell Mol Med 13:3616-31, 2009.

23. Nazarko TY et al. Peroxisomal Atg37 binds Atg30 or palmitoyl-CoA to regulate phagophore formation during pexophagy. J Cell Biol 204:541-57, 2014.

24. Sun $\mathrm{N}$ et al. Measuring in vivo mitophagy. Mol Cell 60:685-96, 2015.

25. Mizushima N, Yoshimori T. How to interpret LC3 immunoblotting. Autophagy7 3:542-5, 2007.

26. Bjørkøy $\mathrm{G}$ et al. Monitoring autophagic degradation of p62/SQSTM1. Methods Enzymol 452:181-97, 2009. 
Tabla 1. Manipulación terapéutica de la autofagia a través de diversas vías de señalización regulatorias ${ }^{1,2,41}$

\begin{tabular}{|c|c|c|}
\hline Vías de señalización & Agente terapéutico & Autofagia \\
\hline \multirow[t]{2}{*}{ AMPc } & Glucagón & \\
\hline & Agonistas y antagonistas adrenérgicos & Activación \\
\hline p53 & Antagonistas beta-adrenérgicos & Inhibición \\
\hline \multirow[t]{3}{*}{ AMPK } & Activador de AMPK (Metformina) & Activación \\
\hline & Inhibidores de AMPK & \\
\hline & & Inhibición \\
\hline mTOR & Inhibidores de mTOR (Rapamicina) & Activación \\
\hline \multirow[t]{2}{*}{ Remodeladores de cromatina } & Inhibidores de histona deacetilasa (HDAC) & Inhibición \\
\hline & activador de sirtuina (resveratrol) & Activación \\
\hline ATG12, ATG5, Beclin1 & Doxorubicina & Inhibición \\
\hline
\end{tabular}

\section{Nodos reguladores de la autofagia}

A través de la colaboración de múltiples grupos de investigación se han identificado vías de señalización claves en la arquitectura molecular de la vía autofágica, y que aparecen como candidatas apetecibles en la modulación de los procesos de autofagia aplicable en distintos escenarios patológicos (Figura 3).

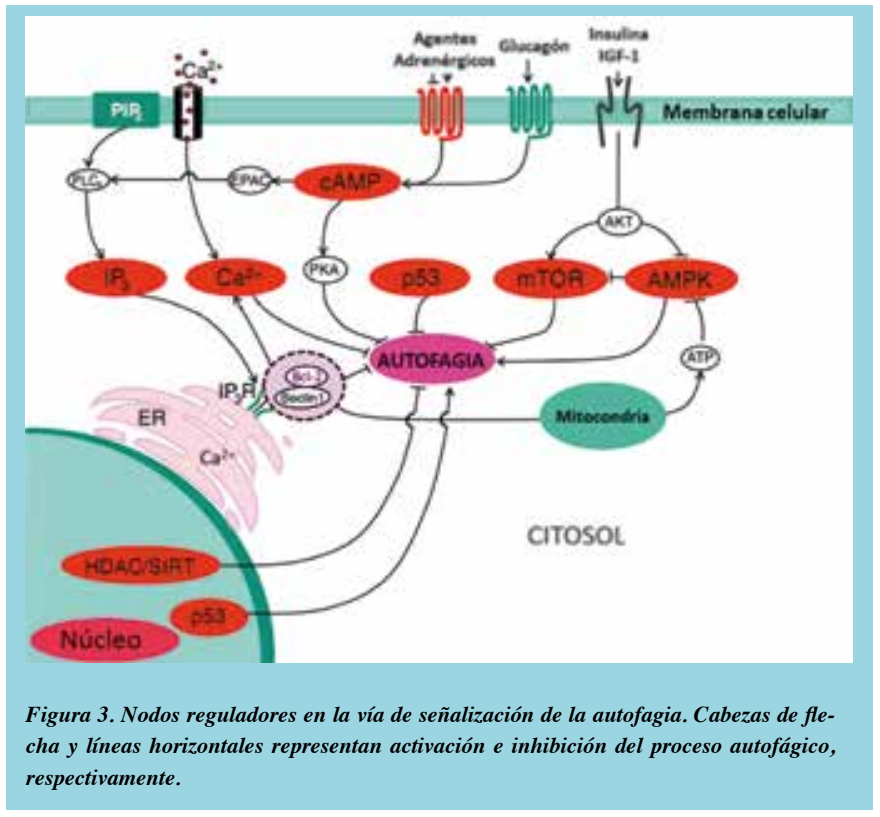

Beclin1/Bcl-2: Promotores fundamentales de la formación del autofagosoma. Beclin1 tiene actividad promotora de autofagia y está inhibida por si interacción con la proteína Bcl-2 bajo condiciones ricas de nutrientes. Ambos son importantes ya que la disociación de Beclin1 de Bcl-2 se requiere para inducir el proceso autofágico ${ }^{1,2}$

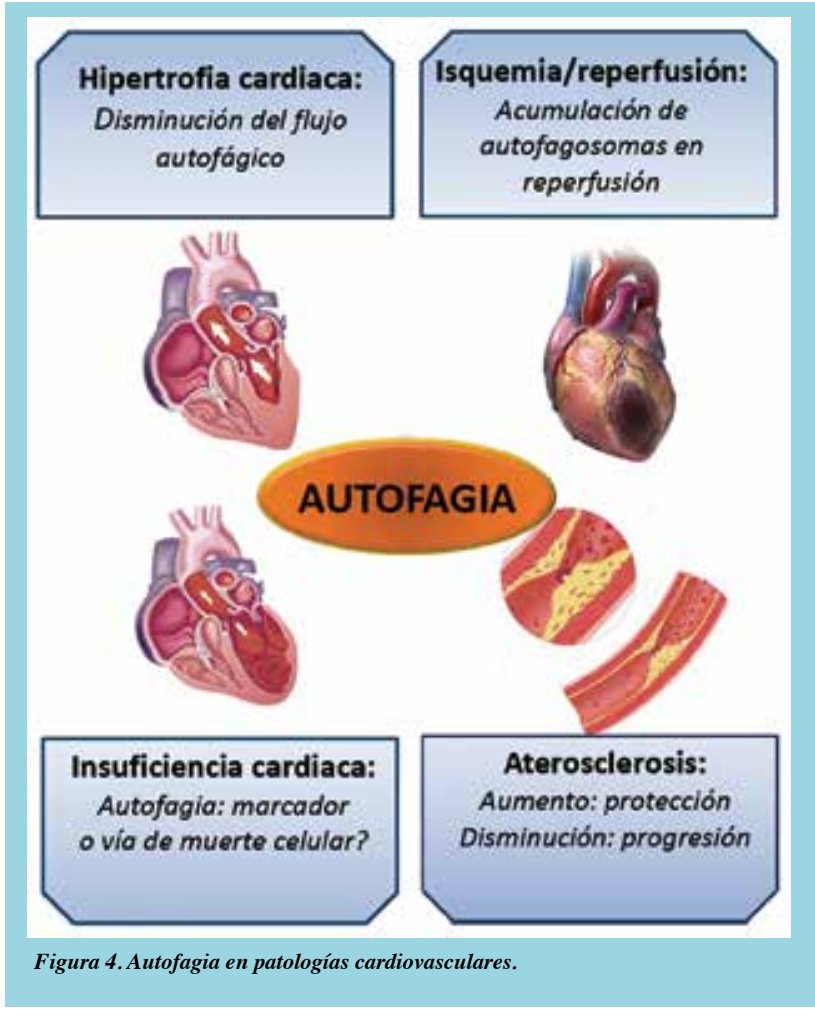

mTORC1: Es un nodo central en el control de la autofagia. Esta quinasa regula el crecimiento celular y el metabolismo en respuesta a los nutrientes, factores de crecimiento, ATP y estrés ${ }^{1,2}$. mTOR existe como dos complejos multiproteicos: TORC1 y TORC2. El complejo TORC1 regula procesos relacionados a crecimiento y autofagia. Se inhibe en situaciones de privación de nutrientes o por rapamicina ${ }^{2}$.

Receptor IP3: El inositol -1, 4, 5- trisfosfato (IP3) y su re- 
ceptor han emergido como importantes reguladores negativos endógenos de la autofagia. Cuando el receptor IP3 no es activado, los niveles de energía bajan, se activa AMPK y la autofagia colabora a preservar la homeostasis energética y la sobrevida celular ${ }^{1,2}$.

AMPK: Esta proteína quinasa heterotrimérica actúa como un integrador de múltiples señales en el control del balance energético. Esta proteína se activa en condiciones de depleción de la energía celular, tales como niveles bajos de ATP o privación de glucosa, induciendo el proceso autofágico..$^{1,2}$

PKA: La proteína quinasa dependiente de AMP cíclico (PKA) es clave en la vía autofágica dado que regula el crecimiento celular en respuesta a nutrientes extracelulares y estrés celular. PKA actúa como regulador negativo de la autofagia, actuando principalmente sobre los componentes que forman el autofagosoma ${ }^{1,2}$.

Factor transcripcional p53: Este factor puede ejercer doble regulación de la autofagia dependiendo de su localización subcelular y modulación de las vías mTOR y AMPK. Interesantemente en el núcleo, este factor tiene una función pro-autofágica, mientras que al localizarse en el citoplasma p53 suprime la inducción de la autofa$\operatorname{gia}^{1,2}$.

\section{Estudio de la autofagia cardiovascular}

En los últimos años diversos estudios han definido el papel de la autofagia en la homeostasis cardiovascular y desarrollo de enfermedades cardiovasculares (Figura 4). En el año 1970, se describió el primer reporte de autofagia en el cardiomiocito, pero sólo recién en el año 2000 se comenzó a realizar una investigación robusta y concluyente acerca de autofagia en sistema cardiovascular, donde se buscó identificar el circuito regulador activador de la autofagia, el procesamiento lisosomal, y determinar las implicancias funcionales de cambios en las vías autofágicas ${ }^{1,2}$.

En el año 2001 se propuso a la autofagia como un posible mecanismo de muerte celular en la cardiomiopatía dilatada ${ }^{17}$. En el año 2004, el grupo de Noburo Mizushima desarrolló un novedoso método para monitorear el proceso autofágico en un organismo completo. Estos investigadores crearon un ratón transgénico que expresa la proteína LC3 (marcador molecular para membranas autofágicas) fusionada a una proteína que emite fluorescencia verde $(\mathrm{GFP})^{18}$. De esta manera monitorearon la autofagia in vivo en los distintos órganos en condiciones basales y de privación de nutrientes. El análisis de autofagia en tejido cardiaco reveló que su nivel era bajo en animales alimentados. Sin embargo, el número y tamaño de los autofagosomas aumentó en el corazón de animales sometidos a ayuno de $48 \mathrm{~h}^{18}$. Posteriormente, este mismo grupo estudió la función de la autofagia durante el período de inanición neonatal temprana en ratones ${ }^{19}$. Al nacer, el suministro constante de nutrientes proporcionados por la placenta se interrumpe abruptamente y el recién nacido padece de hambre severa hasta que recibe los nutrientes en la leche materna. Estos investigadores mostraron que los neonatos se adaptan a esta circunstancia adversa al inducir la autofagia, ya que durante la embriogénesis en nivel de autofagia se mantiene bajo, pero aumenta inmediatamente en varios tejidos (incluyendo el corazón) después del nacimiento y se mantiene alto durante 3 a 12 $\mathrm{h}$ antes de volver al nivel basal ( 1 a 2 días) ${ }^{19}$. Los ratones deficientes para ATG5 (proteína esencial para la formación de autofagosomas) mueren dentro de un día después del parto y presentan reducido el nivel de aminoácidos en el plasma y tejidos con signos de agotamiento energético ${ }^{19}$. Estos hallazgos sugieren que la producción de aminoácidos por degradación autofágica de las proteínas "propias", permite el mantenimiento de la homeostasis energética, posicionando a la autofagia como un mecanismo indispensable de sobrevida.

A través del veloz avance de la biología molecular y su alcance, en los últimos años los aportes más recientes se basaron en la identificación de factores de transcripción claves como promotores de autofagia, así como también otros procesos moleculares que describen alteraciones del proceso de autofagia y su relación con inflamación y daño cardíaco ${ }^{3,9}$.

De lo que se conoce hasta la fecha, la autofagia en el corazón se comporta como una moneda de dos caras, por un lado, confiere protección; y por el otro favorece el avance de diversas patologías cardiovasculares. En este apartado analizaremos la relación entre la autofagia y las enfermedades cardiovasculares más prevalentes.

\section{Autofagia y patologías cardiovasculares}

Hipertrofia cardíaca. Esta es una respuesta adaptativa del corazón en respuesta a una sobrecarga de presión o volumen, a la perdida de proteínas o de masa contráctil debido a isquemia miocárdica. La hipertrofia miocárdica a nivel celular se traduce en el aumento del tamaño celular y de la síntesis proteica ${ }^{20}$. En investigaciones previas se observó que la estenosis aórtica disminuye la actividad 
de autofagia en el cardiomiocito ${ }^{21}$, lo que denota inhibición de la degradación de los productos citoplasmáticos. Los agonistas beta adrenérgicos estimulan el desarrollo de hipertrofia miocárdica. Se ha observado que el agonista beta1/beta2-adrenérgico isoproterenol disminuye la autofagia cardíaca ${ }^{22}$. Al inducir experimentalmente hipertrofia cardíaca en respuesta a sobrecarga de presión, mediante constricción aórtica, se constata disminución de la actividad autofágica del cardiomiocito en la primera semana ${ }^{23}$. Rapamicina, potente activador de la autofagia a través de la inhibición de mTOR, previene la hipertrofia cardíaca inducida por constricción aórtica y hormonas tiroideas ${ }^{24}$. Se puede deducir por lo tanto que existe una relación inversa entre la autofagia y el desarrollo de hipertrofia cardíaca. No obstante, en el estudio realizado por Zhu et al., en el que se realizó una sobrecarga de presión por compresión transversa de la aorta en ratón, se produce un incremento de la actividad de autofagia a las $24 \mathrm{~h}^{25}$. Esta condición de remodelado patológico se previene en ratones con haploinsuficiencia genética de beclin-1 (se expresan niveles significativamente más bajos de la proteína pro autofágica Beclin-1) ${ }^{25}$. Por otra parte, la sobreexpresión genética de beclin-1 amplifica el remodelado hipertrófico patológico en respuesta a la sobrecarga de volumen ${ }^{25}$. Esta función de "doble agente" ya ha sido expuesta en múltiples órganos y patologías. Por lo que se ha postulado que el impacto de la autofagia es un continuo en el que existe un rango óptimo necesario para mantener la homeostasis y función celular ${ }^{26}$. El flujo autofágico es influenciado, a su vez, por la relación $\mathrm{NAD}^{+} / \mathrm{NADH}$. Un aumento de esta relación se asocia a incremento de la actividad autofágica. El aumento de $\mathrm{NAD}^{+}$se ha asociado a un efecto protector frente a la injuria miocárdica ${ }^{27}$. La administración exógena de $\mathrm{NAD}^{+}$ bloquea el desarrollo de hipertrofia inducida por angiotensina II o catecolaminas (adrenalina) ${ }^{28}$. En un modelo de ratas transgénicas que sobrexpresan renina y angiotensinogeno, la restricción calórica disminuyó la mortalidad, cardiomiopatía hipertrófica, inflamación vascular, daño miocárdico y niveles de péptido natriurético auricular (ANP). Estos efectos positivos eran independientes de los cambios de presión arterial y se asociaron al incremento de la actividad autofágica ${ }^{29}$. Recientemente se ha descubierto que una familia de microRNAs que asocia autofagia e hipertrofia cardiaca ${ }^{30}$. De toda esta información se deduce que es posible regular la autofagia a través de los múltiples mecanismos, lo que ofrece entonces la posibilidad de considerarla como blanco terapéutico en la hipertrofia cardíaca patológica.
Insuficiencia cardíaca. El miocardio hipertrofiado patológicamente en respuesta a una sobrecarga de presión crónica tiende a dilatarse acompañado de una pérdida progresiva de la funcionalidad contráctil normal, estableciéndose una insuficiencia cardíaca. Se ha mostrado incremento de actividad autofágica en el miocardio de pacientes con insuficiencia cardiaca ${ }^{23}$. Se ha postulado que la autofagia podría corresponder a una respuesta adaptativa en el miocardio de pacientes con insuficiencia cardíaca frente al déficit de nutrientes. Sin embargo, se desconoce si la autofagia es un marcador de insuficiencia cardíaca o es una vía alternativa de muerte de los cardiomiocitos dañados.

Isquemia-reperfusión. En la injuria miocárdica frente a isquemia/reperfusión se ha observado disminución de la capacidad autofágica, lo que conlleva a un aumento de la injuria celular secundaria a hipoxia ${ }^{24}$. La interrupción de la autofagia conlleva un aumento del daño miocárdico por isquemia ${ }^{31}$. Sin embargo, en la reperfusión, al contrario de lo que uno esperaría, se ha encontrado una marcada acumulación de autofagosomas. Se podría pensar que este aumento en la actividad autofágica se relacionaría con la necesidad de eliminar organelos dañados. Sin embargo, esta hipótesis aún no ha sido demostrada. En el corazón, el número de autofagosomas y el tamaño del infarto se redujeron significativamente en ratones beclin-1 haploinsuficientes ${ }^{31}$. Por otra parte, existe evidencia de que la autofagia participa en la muerte del cardiomiocito frente a la isquemia/reperfusión ${ }^{31}$. Pareciera estar establecido que la autofagia podría cumplir un rol dual durante eventos de isquemia/reperfusión, siendo beneficiosa durante la isquemia y dañina en la reperfusión. Sin embargo, es importante resaltar que la vía de activación de la autofagia durante la isquemia ocurre a través de AMPK y durante la reperfusión es dependiente de Beclin- ${ }^{31}$. La activación de beclin-1 interfiere con la fusión del autogafosoma con el lisosoma, lo que explica que en la reperfusión exista una acumulación de autofagosomas. La activación mTOR parecería ser una vía común de regulación entre autofagia y apoptosis ${ }^{32}$. Esto podría ser útil en escenarios clínicos de isquemia miocárdica esperada como durante la angioplastia y el by-pass coronario.

Disfunción endotelial y aterosclerosis. En condiciones basales la autofagia posee un efecto estabilizador de la placa aterosclerótica ${ }^{1,2}$. A lo largo del tiempo se ha mostrado que existe un aumento de marcadores de la actividad autofágica en placas ateroscleróticas humanas ${ }^{33,34}$. 
A nivel de la placa aterosclerótica se producen o acumulan diversas moléculas que actúan estimulando la autofagia como lo son las especies reactivas del oxígeno ${ }^{35}$, oxi-LDL y TNF- $\alpha^{36,37}$. A partir de estas evidencias se ha sugerido que la autofagia se activa para remover los componentes celulares dañados. La enfermedad aterosclerótica se caracteriza por daño endotelial, acumulación de lípidos, infiltración de células inflamatorias y proliferación de células musculares lisas vasculares y fibroblastos. El análisis de la autofagia en los tipos celulares componentes de la placa ateromatosa ha mostrado diversas evidencias disímiles. La aterosclerosis sucede en vasos con disfunción endotelial. Se ha descrito que ésta se relaciona con un flujo autofágico defectuoso. En pacientes diabéticos se logró reversión de la disfunción endotelial con la administración de un activador de la autofagia ${ }^{38}$. A nivel de la célula muscular lisa vascular, la actividad autofágica deficiente favorece el desarrollo de aterosclerosis y re estenosis de los vasos sanguíneos. En macrófagos; una autofagia defectuosa conlleva a hiperactivación del inflamasoma y progresión de la placa ateromatosa ${ }^{39}$. En la etapa temprana de la formación de la placa aterosclerótica, la autofagia se encuentra aumentada y tendría una acción protectora tanto en la célula muscular lisa, endotelial y en los macrófagos ${ }^{39}$. Sin embargo, en estados avanzados, una autofagia defectuosa lleva a estrés severo en las células que componen la placa ${ }^{41}$.

\section{Autofagia cardiovascular: "MADE IN CHILE"}

En Chile, el estudio de la autofagia en el sistema cardiovascular se ha abordado desde una perspectiva básica y clínica, en donde el trabajo colaborativo de varios grupos de investigación ha aportado con los siguientes novedosos hallazgos:

\section{a) Activación de la autofagia cardíaca basal para re-} gular cardiotoxicidad inducida por doxorrubicina $\mathbf{4 1}^{\mathbf{}}$. Este medicamento es uno de los más efectivos agentes antineoplásicos, pero su cardiotoxicidad ha sido su importante limitación clínica. Su cardiotoxicidad se ha asociado al daño oxidativa sobre el cardiomiocito. Aunque varios estudios han sugerido que doxorrubicina altera la autofagia cardíaca, hasta la fecha aún no está claro cómo este antineoplásico altera este proceso y sus consecuencias sobre la viabilidad del cardiomiocito. El trabajo colaborativo de los grupos de los Dres. Sergio Lavandero (Universidad de Chile) y Pablo Castro (P. Universidad Católica de Chile) mostró que doxorrubicina inhibe la autofagia basal en cultivos primarios de cardiomiocitos de rata a través de la activación de la vía de señalización de Akt/mTOR y disminución de los niveles de Beclin $1^{41}$. Este estudio sugiere que este fármaco inhibe la autofagia basal y contribuye a la muerte del cardiomiocito ${ }^{41}$.

b) Acción cardioprotectora del IGF-1. Este péptido ha mostrado rescatar el metabolismo mitocondrial y estado energético del cardiomiocito expuesto a estrés nutricional, reduce la muerte celular y controla una respuesta autofágica excesiva ${ }^{42}$. IGF-1 regula entre otros procesos, el metabolismo, la apoptosis y la autofagia cardíaca y su deficiencia se asocia con mayor riesgo de enfermedad cardiovascular, mientras que la activación de su receptor protege de los efectos perjudiciales de una dieta rica en grasas y del infarto del miocardio ${ }^{42}$. El grupo de investigación del Dr. Sergio Lavandero (Universidad de Chile) evaluó el efecto de estrés nutricional en cardiomiocitos cultivados y en ratones sometidos a ayuno y que genéticamente expresan menos niveles plasmáticos de IGF-1. En ambos modelos el estrés nutricional activó la autofagia y muerte celular, siendo ambas respuestas inhibidas por IGF $1^{42,43}$. Por lo tanto, este factor podría ser beneficioso para mitigar el daño inducido por estrés nutricional excesivo, incluyendo la enfermedad isquémica en diversos tejidos.

c) La proteína Herp un nuevo regulador de la autofa$\mathbf{g i a}^{\mathbf{4 4}}$. Herp es una proteína inducible por estrés y participa en la vía de degradación de las proteínas asociadas con el retículo endoplásmico. Nuestro estudio mostró que Herp estimula la autofagia y contribuye a la eliminación de agregados proteicos poli-ubiquitinados por efecto de inhibición del proteasoma y falta de glucosa, lo que también resultó en protección de la muerte ${ }^{44}$. Estos resultados sugirieron que Herp podría regular estados patológicos tales como isquemia cerebral y cardiaca, condiciones asociadas al estrés nutricional agudo.

d) Regulación de la autofagia en el fibroblasto cardíaco por beta-bloqueadores adrenérgicos ${ }^{45}$. Estas células son fundamentales en la homeostasis cardíaca, expresan el receptor beta adrenérgico y la activación del sistema adrenérgico se asocia con fibrosis cardíaca ${ }^{46}$. Este trabajo del grupo del Dr. Guillermo Díaz-Araya (Universidad de Chile) evaluó el efecto de la estimulación de esta vía sobre autofagia del fibroblasto cardíaco, concluyendo que los beta bloqueadores regulan la autofagia, la cual podría contribuir a reducir los efectos dañinos de una elevada estimulación adrenérgica sobre la fibrosis cardíaca ${ }^{47}$. 
e) Alteración de la autofagia cardíaca en la fibrilación auricular post-operatoria ${ }^{48}$. Anteriormente, Mariscalco et $\mathrm{al}^{49}$ detectaron anomalías histológicas como fibrosis intersticial y vacuolización en muestras auriculares de pacientes sometidos a cirugía de revascularización miocárdica. Un estudio colaborativo entre los equipos de los Dres. Ramón Corbalán (P. Universidad Católica de Chile) y Lorena García (Universidad de Chile) utilizó muestras de orejuela de aurícula derecha de pacientes con y sin fibrilación auricular post-operatoria y evaluó el remodelado cardíaco por microscopía óptica y electrónica y autofagia mediante el procesamiento de LC3 por Western blot. Las microfotografías electrónicas mostraron una acumulación significativa de vesículas autofágicas y depósitos de lipofuscina y un procesamiento de LC3 marcadamente menor en muestras de pacientes con fibrilación auricular48. Este estudio sugirió un deterioro selectivo del flujo autofágico cardíaco en pacientes que desarrollan esta arritmia después de la cirugía de bypass coronario ${ }^{48}$.

Nuevas perspectivas: autofagia como blanco terapéutico La autofagia cardiovascular se ha planteado como una vía de control de calidad de proteínas que tiene relevancia clínica $^{1,2}$. Independiente de los avances alcanzados en terapias cardiovasculares, la incidencia de insuficiencia cardíaca permanece alta, lo que se atribuye al incompleto entendimiento de procesos de plasticidad cardíaca y remodelado patológico. Mientras que niveles basales de autofagia son requeridos para la sobrevida celular, niveles descontrolados pueden contribuir a la patogénesis. En cualquier evento, la prevalencia de la activación de autofagia en la mayoría de los desórdenes cardíacos, sugiere la activación de una vía de señalización celular en común, y ésta aparece como blanco para alguna ganancia terapéutica ${ }^{49}$. Actualmente, existen diversos agentes terapéuticos que modulan positiva o negativa del proceso de autofagia, a través de su intervención a diferentes niveles de las diferentes vías de señalización involucradas en el mecanismo de la autofagia; dichos abordajes farmacológicos han sido mostrados y probados in vitro $\mathrm{y}$ algunos ya in vivo, figurando así diversas estrategias a nivel celular y molecular como fuertes candidatos para la activación o inhibición de procesos de autofagia, aplicable a patologías cardiovasculares según convenga (Tabla 1). En cuanto a aplicaciones putativas en enfermedades cardiovasculares, se han patentado numerosos compuestos que en base a su capacidad de inducir autofagia han sido propuestos para su uso en isquemia miocárdica y aterosclerosis, mientras que aquellos compuestos capaces de inhibir o regular los procesos de autofagia y muerte por autofagia han sido diseñados para ejercer su acción en patologías de tipo inflamatorias, vasculares hiperproliferativas, fibróticas e hipertróficas ${ }^{50-58}$. Incluso, ha sido descrito que la cardiotoxicidad inducida por Doxorubicina, estaría directamente relacionada con la activación del proceso de autofagia por parte de este fármaco ${ }^{41}$.

\section{Agradecimientos}

Este trabajo se financiado por el proyecto FONDAP 15130011 (SL, LG), Proyectos FONDECYT 1140713 (LG), 3160086 (MNC). 


\section{Referencias:}

1. LAVANDERO S, TRONCOSO R, ROTHERMEL BA, MARTINET W, SADOSHIMA J, HILL JA. Cardiovascular autophagy: concepts, controversies, and perspectives. Autophagy 2013; 9:1455-1466.

2. LAVANDERO S, CHIONG M, ROTHERMEL BA, HILL JA Autophagy in cardiovascular biology. J Clin Invest, 2015;125: 56-64.

3. MIZUSHIMA N, LEVINE B. Autophagy in mammalian development and differentiation. Nat Cell Biol.2010; 12:823-30.

4. NEMCHENKO A, CHIONG M, TURER A, LAVANDERO S, HILL JA. Autophagy as a therapeutic target in cardiovascular disease. J Mol Cell Cardiol 2011; 51 : 584-593.

5. DETER RL, DE DUVE C. Influence of glucagon, an inducer of cellular autophagy, on some physical properties of rat liver lysosomes. J Cell Biol 1967; 33:437-49.

6. MIZUSHIMA N, YOSHIMORI T, OHSUMI Y. The role of Atg proteins in autophagosome formation. Annu Rev Cell Dev Biol, 2011; 27:107-32.

7. TSUKADA M, OHSUMI Y. Isolation and characterization of autophagy-defective mutants of Saccharomyces cervisiae. FEBS Lett, 1993; 333, 169-174.

8. TAKESHIGE K, BABA M, TSUBOI S, NODA T, OHSUMI Y. Autophagy in yeast demonstrated with proteinase-deficient mutants and conditions for its induction. J Cell Biol, 1992; $119,301-311$

9. KROEMER G, MARIÑO G, LEVINE B. Autophagy and the integrated stress response. Mol Cell, 2010; 40:280-293.

10. MIZUSHIMA N. The role of the Atg1/ULK1 complex in autophagy regulation. Curr Opin Cell Biol 2010; 22:132-9.

11. HAILEY DW, RAMBOLD AS, SATPUTE-KRISHNAN P, MITRA K, SOUGRAT R, KIM PK, et al. Mitochondria supply membranes for autophagosome biogenesis during starvation. Cell, 2010; 141, 656-667.

12. GRAEF M, FRIEDMAN JR, GRAHAM C, BABU M, NUNNARI J. ER exit sites are physical and functional core autophagosome biogenesis components. Mol Biol Cell, 2013; 24, 2918-2931.

13. KOMATSU M, WAGURI S, UENO T, IWATA J, MURATA S, TANIDA I,et al. Impairment of starvation-induced and constitutive autophagy in Atg7-deficient mice. J. Cell Biol. 2005;
$169,425-434$.

14. KLIONSKY DJ, SCHULMAN BA. Dynamic regulation of macroautophagy by distinctive, ubiquitin-like proteins. Nature Struct Mol Biol, 2014; 21, 336-345.

15. STOLZ A, ERNST A, DIKIC I. Cargo recognition and trafficking in selective autophagy. Nat Cell Biol. 2014; 16:495-501.

16. ZHOU J, TAN SH, NICOLAS V, BAUVY C, YANG ND, ZHANG J, et al. Activation of lysosomal function in the course of autophagy via mTORC1 suppression and autophagosome-lysosome fusion. Cell Res, 2013; 23:508-23.

17. SHIMOMURA H, TERASAKI F, HAYASHI T, KITAURA Y, ISOMURA T, SUMA H. Autophagic degeneration as a possible mechanism of myocardial cell death in dilated cardiomyopathy. Jpn Circ J, 2001; 65:965-8.

18. MIZUSHIMA N, YAMAMOTO A, MATSUI M, YOSHIMORI T, OHSUMI Y. In vivo analysis of autophagy in response to nutrient starvation using transgenic mice expressing a fluorescent autophagosome marker. Mol Biol Cell. 2004;15:1101-11.

19. KUMA A, HATANO M, MATSUI M, YAMAMOTO A, NAKAYA H, YOSHIMORI T, et al. The role of autophagy during the early neonatal starvation period. Nature. 2004;432:1032-6.

20. FREY N, KATUS HA, OLSON EN, HILL JA. Hypertrohpy of the heart. Circulation 2004; 109:1580-1589.

21. DÄMMRICH J, PFEIFER U. Cardiac hypertrophy in rats after supravalvular aortic constriction. I. Size and number of cardiomyocytes, endothelial and interstitial cells. Virchows Arch B Cell Pathol Incl Mol Pathol, 1983; 43:287-307.

22. PFEIFER U, FOHR J, WILHELM W, DAMMRICH J. Shortterm inhibition of cardiac celular autophagy by isoproterenol. J Mol Cell Cardiol 1987; 19: 1179-1184.

23. NAKAI A, YAMAGUCHI O, TAKEDA T, HIGUCHI Y, HIKOSO S, TANIIKE M, et al. The role of autophagy in cardiomyocytes in the basal state and in response to hemodynamic stress. Nat Med. 2007.; 13:619-24.

24. NISHIDA K, KYOI S, YAMAGUCHI O, SADOSHIMA J, OTSU K. The role of autophagy in the heart. Cell Death Differ 2009; 16: 31-8.

25. ZHU H, TANNOUS P, JOHNSTONE JL, KONG Y, SHELTON JM, RICHARDSON JA, et al. Cardiac autophagy is a 
maladaptive response to hemodynamic stress. J Clin Invest 2007; 117:1782-93.

26. Rothermel BA, Hill JA. Autophagy in load-induced heart disease. Circ Res.2008; 103:1363-1369.

27. HSU CP, HARIHARAN N, ALCENDOR RR, OKA S, SADOSHIMA J. Nicotinamide phosphoribosyltransferase regulates cell survival through autophagy in cardiomyocytes. Autophagy 2009; 5:1229-1231.

28. PILLAI VB, SUNDARESAN NR, KIM G, GUPTA M, RAJAMOHAN SB, PILLAI JB, et al. Exogenous NAD blocks cardiac hypertrophic response via activation of the SIRT3-LKB1-AMP-activated kinase pathway. J Biol Chem. 2010; 285:3133-3144.

29. FINCKENBERG P, ERIKSSON O, BAUMANN M, MERASTO S, LALOWSKI MM, LEVIJOKI J, et al. Caloric restriction ameliorates angiotensin II-induced mitocondrial remodeling and cardiac hypertrophy. Hypertension. 2012; 59:76-84.

30. KNAAPEN MW, DAVIES MJ, DE BIE M, HAVEN AJ, MARTINET W, KOCKX MM. Apoptotic versus autophagic cell death in heart failure. Cardiovasc Res; 2001; 51: 304-312.

31. MATSUI Y, TAKAGI H, QU X, ABDELLATIF M, SAKODA $\mathrm{H}$, ASANO $\mathrm{T}$, et al. Distinct roles of autophagy in the heart during ischemia and reperfusion: roles of AMP-activated protein kinase and Beclin 1 in mediating autophagy. Circ Res 2007; 100: 914-922.

32. MAIURI MC, ZALCKVAR E, KIMCHI A, KROEMER G. Self-eating and self-killing: crosstalk between autophagy and apoptosis. Nat Rev Mol Cell Biol. 2007; 8: 741-52.

33. MARTINET W, DE MEYER GR. Autophagy in atherosclerosis: a cell survival and death phenomenon with therapeutic potential. Circ Res 2009; 104:304-317.

34. JIA G, CHENG G, GANGAHAR DM, AGRAWAL DK. Insulin-like growth factor-1 and TNF $\alpha$ regulate autophagy through c-jun $\mathrm{N}$-terminal kinase and Akt pathways in human atherosclerotic vascular smooth cells. Immunol Cell Biol. 2006; 84:448-454..

35. SCHERZ-SHOUVAL R, ELAZAR Z. Regulation of autophagy by ROS: physiology and pathology. Trends Biochem Sci. $2011 ; 36: 30-38$.

36. MULLER C, SALVAYRE R, NEGRE-SALVAYRE A, VINDIS C. Oxidized LDLs trigger endoplasmic reticulum stress and autophagy: prevention by HDLs. Autophagy. 2011; 7:541-543.
37. NOWICKI M, ZABIRNYK O, DUERRSCHMIDT N, BORLAK J, SPANEL-BOROWSKI K. No upregulation of lectinlike oxidized low-density lipoprotein receptor-1 in serum-deprived EA.hy926 endothelial cells under oxLDL exposure, but increase in autophagy. Eur J Cell Biol. 2007; 86: 605-616.

38. FETTERMAN JL, HOLBROOK M, FLINT N, FENG B, BRET'ON-ROMERO R, LINDER EA, et al. Restoration of autophagy in endothelial cells from patients with diabetes mellitus improves nitric oxide signaling. Atherosclerosis 2016; 247: 207-217.

39. RAZANI B, FENG C, COLEMAN T, EMANUEL R, WEN $\mathrm{H}, \mathrm{HWANG} \mathrm{S}$, et al. Autophagy links inflammasomes to atherosclerotic progression. Cell Metab. 2012; 15: 534-544.

40. DE MEYER GR, GROOTAERT MO, MICHIELS CF, KURDI A, SCHRIJVERS DM, et al. Autophagy in vascular disease. Circ. Res. 2015; 116 468-479, 2015.

41. PIZARRO M, TRONCOSO R, MARTÍNEZ GJ, CHIONG M, CASTRO PF, LAVANDERO S. Basal autophagy protects cardiomyocytes from doxorubicin-induced toxicity. Toxicology 2016; 370: 41-48.

42. TRONCOSO R, VICENCIO JM, PARRA V, NEMCHENKO A, KAWASHIMA Y, DEL CAMPO A, et al. Energy-preserving effects of IGF-1 antagonize starvation-induced cardiac autophagy. Cardiovasc Res 2012; 93:320-9..

43. TRONCOSO R, IBARRA C, VICENCIO JM, JAIMOVICH E, LAVANDERO S. New insights into IGF 1 signaling in the heart. Trends Endocrinol Metab. 2014; 25:128-37.

44. QUIROGA C, GATICA D, PAREDES F, BRAVO R, TRONCOSO R, PEDROZO Z, et al. Herp depletion protects from protein aggregation by up-regulating autophagy. Biochim Biophys Acta 2013; 1833: 3295-305.

45. ARÁNGUIZ-URROZ P, CANALES J, COPAJA M, TRONCOSO R, VICENCIO JM, CARRILLO C, et al. Beta(2)-adrenergic receptor regulates cardiac fibroblast autophagy and collagen degradation. Biochim Biophys Acta 2011; 1812:23-31.

46. BRISTOW MR, GINSBURG R, UMANS V, FOWLER M, MINOBE W, RASMUSSEN R, et al. Beta1- and beta2-adrenergic-receptor subpopulations in nonfailing and failing human ventricular myocardium: coupling of both receptor subtypes to muscle contraction and selective beta 1-receptor down-regulation in heart failure. Circ Res 1986; 59:297-309.

47. GARCIA L, VERDEJO HE, KUZMICIC J, ZALAQUETT $\mathrm{R}$, GONZALEZ S, LAVANDERO S, et al. Impaired cardiac autophagy in patients developing postoperative atrial fibrillation. J Thorac Cardiovasc Surg 2012; 143:451-9. 
48. MARISCALCO G, KLERSY C, ZANOBINI M, BANACH $M$, FERRARESE S, BORSANI $P$, et al. Atrial fibrillation after isolated coronary surgery affects late survival. Circulation 2008; 118:1612-8.

49. RIFKI OF, HILL JA. Cardiac autophagy: good with the bad. J Cardiovasc Pharmacol 2012; 60: 248-252.

50. METCALF C, ROZAMUS L, WANG Y, BERSTEIN D. Phosphorus-containing compounds and uses thereof. United States patent US 20040073024. 2004 Apr 15.

51. BURDEN S, LITTMAN D. Methods and agents for maintaining muscle mass and for preventing muscle atrophy and biomarkers for monitoring same. United States patent US 2006003959. 2006 Jan 5.

52. FUJIWARA H, TAKEMURA G. Medical composition for treating ischemic cardiac failure. United States patent US 2006051318. 2006 Mar 9.

53. BORGNE A, REBOUILLAT D, JACOTOT E. Means for regulating the expression of human isoforms of ANT. United States patent US 20060210535. 2006 Sept 21.

54. BRADNER J, JP. S, PERLSTEIN E, RUBINSZTEIN D, SARKAR S, SCHREIBER S. Regulating autophagy. Interna- tional patent WO 2008122038. 2008 Oct 9.

55. ARTHUR G, BITTMAN R. The use of glycosylated antitumor ether lipids to induce and/ or enhance autophagy for treatment of diseases. International patent WO 2009092170. 2009 Jul 30 .

56. YUE Z, ZHONG Y. Novel autophagy regulators ATG14L and Rubicon. International patent WO 2010030936. 2010 Mar 18.

57. LANSBURY JR P, JUSTMAN C, GRAMMATOPOULOS T, LYNCH B, LIU Z. Treatment of proteinopathies using a farnesyl transferase inhibitor. United States patent US 2010160372. 2010 Jun 24

58. BROWN D, HUSBAND A, MOR G. Method for inducing autophagy. United States patent US 2010173983. 2010 Jul 8.

59. SYBERS HD, INGWALL J, DELUCA M. Autophagy in cardiac myocytes. Recent Adv Stud Cardiac Struct Metab 12:453-63, 1976.

60. CAO DJ, JIANG N, BLAGG A, JOHNSTONE JL, GONDALIA R, OH M, et al. J Am Heart Assoc. Mechanical unloading activates FoxO3 to trigger Bnip3-dependent cardiomyocyte atrophy. 2:e000016, 2013. 